\title{
KRONiK
}

\section{Kasım Seçimi ve Sonuçlarına Dair}

Yrd. Doç. Dr. Alev Özkazanç, A.Ü. Siyasal Bilgiler Fakültesi

3 Kasım seçimlerinin üzerinden henüz çok kısa bir süre geçmesine rağmen, AKP hükümeti hızlandırılmış gündemin de etkisiyle son derece tempolu ve tartışmalı bir performans sergilemeye başladı bile. Seçimden bir hafta sonra yapılan bir konuşmaya dayanan bu yazıda* bu çok tartışmalı performansın detaylarına girmekten ziyade Türkiye'nin son yirmi ylllık dönüşümü bağlamında yeni döneme dair bazı genel saptamalar yapmakla yetineceğim.

Temel tezimi şöyle özetleyebilirim: 3 Kasım seçim sonuçlarıyla Türkiye 90'lı yılların sonuna işaret eden yeni bir döneme girmiştir. Bu dönemin önemi, Türkiye'de burjuva hegemonyanın tarihsel kuruluşu açısından yeni bir evreye işaret ediyor olmasıdır. Seçimin yolaçtığı yeni iktidar ve meclis yapısı bu hegemonyanun tesisi açısından ciddi bir potansiyel sergilemekte ama ayn zamanda yeni risklere de kapı aralamaktadır.

Bu tezi açıklamak için öncelikle 3 Kasım seçimleriyle sonuçlanan kriz sürecini çözümlemek gerekiyor. Sözkonusu krizin, son koalisyon dönemindeki gündelik politikanın sergilediği son derece girift ama yüzeysel görüngüler üzerinden değil, (Ecevit'in sağlığı üzerinden geliştirilen ve 'komplo' olarak analiz edilen tüm bir süreç) daha geriden ve dipten gelen bir kriz bağlamında analiz edilmesi doğru olacaktur. Bu kriz kabaca 80 'li yıllarda tohumları atılan ve 90 'larda giderek şiddetlenen bütünsel bir hegemonya krizi olarak tarif edilebilir. 1980'li yllar Türkiye'de burjuva hegemonyasının tarihsel kuruluşu açsından yeni bir açlım sağlamış ancak belirli kriz potansiyellerini de harekete geçirmişti. Sözkonusu kriz eğilimlerinin tümünün 90'lar boyunca gerçekleştiğini gördük. 90'ların krizinin tohumları 80'lerde belirli bir birikim stratejisi ile buna paralel olarak belirli bir siyasal yapınun dayatılmasıyla atılmıs ve bu iki alan arasındaki ilişkilerden ve bunların kendi içsel gerilimlerinden beslenerek büyümüştü. Bu kriz 90'ların sonuna yaklaşıldığında, birikim stratejisi krizinin yanısıra temsil, meşruiyet, devlet rasyonalitesi gibi boyutları da içeren çok boyutlu ve derin bir

* Bu yazı, 8 Kasım 2002 tarihinde SBF Asistan Toplantıları çerçevesinde düzenlenen 3 Kasım Seçimleri konulu toplantıda yapılan konuşmanın gözden geçirilmiş halidir. Metnin tüm orjinal vurguları korunmuş, ancak konuşma tarihinden sonraki gelişmelere dair saptamalar ile yazının sonundaki 'kişisel not' bölümü bu yazı için sonradan eklenmiştir. AKP hükümetinin son günlerde kaŗ̧ı karşıya kaldığı 'savaş' konjonktürü, bu yazıda sunulan analizi doğrudan etkileyecek bir nitelik taşıdığı halde, bu sorun orijinal konuşma metninde ele alınmadığı ve daha ayrıntılı bir analiz gerektirdiği için, bu yazıda da dışanda bırakılmıştır. 
organik kriz şeklini almışt. Krizin merkezinde, devletin stratejik bir zemin olarak burjuvazinin uzun dönemli hegemonik çkarlarının gerçekleşmesi açısından giderek daha fazla işlev bozukluğu sergilemesi yatıyordu. 80'lerin ihracata dönük neo-liberal büyüme stratejisi, başlangıçta ona uygun olarak yeniden yapılandırılan siyasal alanun sergilediği özgül dinamiklerin de etkisiyle dönüşerek 90 larda siyasetçi-bürokrat-sermaye üçlüsünün işbirliğinde bir yolsuzluk ekonomisi şeklini almışt. Sonuçta devlet, burjuvazinin uzun dönemli çıkarları ile bağımlı toplumsal sınıfların taleplerini birbirine eklemleyen hegemonik stratejilerin geliştirilebildiği stratejik bir zemin olma kapasitesini tamamen yitirerek, giderek darlaşan bir iktidar bloğunun elindeki basit bir rant paylaşma arac haline dönüştü. Bu işleyiş, uzun vadede başarılı bir birikim stratejisi için gerekli olan üretken sermayenin de altın oymaya başlamıştı. Öte yandan partili-temsili siyaset, tamamen, kamu olanaklarınun partinin iktidarınun sürmesi için gerekli olan 'popülist-yanaşmaci' amaçlarla kullanilması ve bu 'iktidari' elde tutmak için girişilen entrikalar dizisine indirgenmişti. 80'lerde çizilen anayasal ve yasal cendere içine sıkıştırılan temsili siyaset pratiği yirmi yılın sonunda, partiler ile temsil etme iddiasında oldukları kesimler arasındaki bağların tümüyle zedelendiği, merkez sağ-sol partilerin Türkiye'nin kaderini belirleyen temel siyasi sorunların tümü konusunda çözümsüzlük üreten bir 'devlet politikasına' hapsedildiği (burada 28 Şubat müdahalesinin ve Kürt sorunundaki militarist tavrın kendi çapında bir 'açılım' getirdiği itiraf edilmeli) ve sonuçta genel olarak siyaset pratiğinin geniş kitleler nezninde ciddi bir meşruiyet kriziyle karşlaştığı bir tür kendi kendini imha harekat görünümü sergilemeye başlamışt. Bu tür bir siyasi arenanın geri planında ise, devlet politikasının koyduğu sınurlar içinde partiler-arası rekabetin ana malzemesini sağlamanın ötesinde demokratik bir 'politik' açlım getirilmeksizin kangrene dönüşen iki temel sorun olarak laik-anti-laik çatşması ile Kürt sorunu bulunuyordu. Sözkonusu iki temel yarılma/çatışma dinamiği süreç içinde giderek keskinleşerek toplumun, parti rekabetinin şiddetini de aşan derin bir bölünme, kutuplaşma ve içine kapanma refleksi vermesiyle sonuçland. Sonunda Türkiye toplumu 'merkezin' giderek radikal sağa kaydığı, merkez sağ-sol kimliklerinin anlamsızlaştığı, paranoyak korkuların ve nefretin kışkırtılması üzerinden işleyen bir 'devlet politikasının' hakim olduğu ve artan sosyal sefaletin dayanılmaz boyutlara vardığı son derece vahim bir atmosfere teslim oldu. 90'ların siyasal alanının temel bir özelliği de sözkonusu tüm bu toplumsal ve siyasal çatı̧̧aların küreselleşme bağlamının yarattğı refleksler üzerinden şekillenmesiydi. Türkiye'nin egemenleri, izledikleri iktisadi-siyasi rotanın giderek daha fazla anti-hegemonik olmaya başladığını, geniş halk kesimlerinin rızasını örgütleme kapasitelerinin giderek azaldığın daha net anladıkları her uğrakta, 'Türkiye'nin tüm dünyanun ve özellikle 'Bat'nun şer güçlerinin tehdidi altında beka davasıyla yüzleşen mağdur ama onurlu bir ülke olduğu' söylemine daha da fazla yaslanmaya başladılar. Böylece 'devlet 
politikası', bir yanda kendini dayatan 'küresel' tazyiklerin gerektirdiği reformlann kaçnılmazlığının kabulü ile küresel momente verilen içe kapanmacı-otoriter-devletçi reaksiyon arasında şizofrenik bir bölünme sergilemeye başladı. 90'lann sonuna yaklaşırken artık temel yarılma/çatışma ekseni, otoriter-devletçi-içe kapanmac ile liberal-küresel arasında kuruluyordu.

Öcalan'ın yakalanması konjonktüründe gerçekleşen 18 Nisan seçimleriyle oluşan koalisyon hükümeti, önünde DSP ve MHP'ye verilen seçmen desteğiyle hiç ilgisi olmayan 'nesnel' bir program buldu ve bu programi son derece uyumlu biçimde uygulamaya koyuldu. Koalisyonun bu derece uyumlu çahşmasını mümkün ve zorunlu kılan, organik krizin yolaçth̆̆ düğümü çözmeye yönelik projenin hatlarınin en nihayet 'olgunlaşması' ve kendini yeni bir 'devlet politikası' olarak dayatmaya başlamasıydı. Krizin çözümüne yönelik bu program, siyasi ve iktisadi olarak küresel entegrasyon hedefine işaret eden AB'ye giriş hedefi üzerinden şekillenmişti. $A B$, siyasi demokratikleşme ile ekonomik rasyonelleşme hedefini birbirine bağlı olarak dayatan-zorlayan (ve dolayısıyla burjuvazinin uzun vadeli hegemonik çıarlarına uygun) bir proje olarak, burjuvaziye bir kurtuluş simidi gibi görünmeye başladı. Ancak büyük şizofrenik bölünme devam ediyordu. Yapılması gereken ile statükonun dayattıkları (mevcut tüm çıkar, mevki, söylem, duygu, tutumlar bütünü) arasındaki uçurum hala çok büyüktü. Bu çkmaz noktada Türkiye'nin egemenlik zihniyeti, reformcu çözümü her zamanki gibi kendine 'dışsallaştırdığı' bir güç üzerinden ifade etme yolunu tercih etti. AB'ye girişin, mevcut siyasi ana akıntıya ters olmasına rağmen, zorunlu olarak ve ancak bir 'devlet politikasi' olarak benimsenebilmiş olması bu şizofrenik zihniyetin bulabildiği tek çözümdü. Sözkonusu bu yeni 'devlet politikası', geniş halk kitlelerinin rızasın örgütlemeksizin onlara üstten dayatllyor olması vasfiyla mevcut devlet zihniyetiyle süreklilik taşıyordu. Öte yandan Türkiye'nin son yirmi yllının- hatta tüm cumhuriyet tarihinin- temel bazı yapılarınn radikal dönüşümünü gerektirdiği oranda aslında son derece zayıf bir siyasal-toplumsal temele dayanyordu. Tam da bu nedenle kimsenin bu proje konusunda içeriden bir toplumsal desteği örgütleme kapasite ve cesareti olmadığı için (çünkü bu tür bir mobilizasyon zaten her an denetimden çımaya hazır 'demokratikleşme' gibi bir söylemin 'arzu edilmeyen' noktalara varmasına yolaçabilirdi) devlet, bu dönüşümün gerekliliğini dışsal bir dayatmanın (ama devletin 'ali çıkarları' için gönülsüz de olsa nza gösterilmesi gereken bir dayatma) sonucu olarak kabullenmeye mahkumdu. Ecevit başkanlı̆̆ındaki koalisyonun dağılmasına ve 3 Kasım seçimlerine götüren karmaşık süreç, asıl olarak koalisyonun şizofrenik biçimde yüklendiği bu 'nesnel' programı yerine getirmek konusunda ayak diremeye başlaması, yani MHP'nin AB konusundaki giderek netleşmeye başlayan direnişi karşısında koalisyonun devamı lehine tavır almasıyla tetiklenmişti. Aslında koalisyon bu 'davanın' yerine getirilmesi için elinden 
geleni yapmış, özellikle Şubat krizinin ardından artık 90'ls yılların siyaset-ekonomi ilişkilerinin yapısal bir dönüşüme ihtiyaç gösterdiğini teslim ederek, IMF (ve AB'nin) sadece krizin acil yönetiminin kuralların değil, uzun vadeli yapısal dönüşümleri de dayatan 'rasyonelleştirici' programın da uygulamaya başlamışt. Hatta koalisyon, ancak 'kendini aşma' olarak tarif edilebilecek son bir sürpriz hamle yaparak giderayak uyum yasaların bile çıkarmışt. Ancak bu şizofrenik tavrın son bulması ve siyasi arenanun daha da sadeleşmesi için yeni bir seçim kaçınulmaz olmuştu. Dolayısıyla seçimler öncesinde siyasal alan, 90'l yulların kısır parti rekabetini aşan bir tarzda güçlerin daha sade ve anlamì bir kamplaşmaya doğru şekillendiği; siyasi öznelerin artık ana hatlarıyla iyice netleşmiş bir 'dava'yı sahiplenmeye niyeti olanlar ile olmayanlar arasındaki ayrım üzerinden bölünmeye başladıkları bir görünüm sergiliyordu. Seçim öncesinde önceleri YTP sonra da Derviş'in yön değiştirmesiyle CHP'ye gösterilen ilgi sözkonusu 'programi' sahiplenecek herhangi bir siyasi irade arayışının göstergesiydi.

3 Kasım seçimlerinin sonucu, yani AKP'nin son on yllın koalisyonlar dönemine son veren büyük seçim zaferinin yansıra, $\mathrm{CHP}$ dışında eski döneme damgasını vuran partilerin tümünün meclis dışında kaldığı iki partili bir meclis yapısının oluşması, 90'lı yılların sonuna işaret eden ve burjuva hegemonyanın kurulması için bir açlım sağlayan sürpriz bir gelişme olarak görülebilir. Sandıktan çkan sürpriz güç, bu dava için burjuvazi tarafından özel olarak hazırlanmadığı /pazarlanmadığı halde -hiç kuşkusuz tam da bu nedenle- sözkonusu davanın örgütleyicisi olma konusunda diğer tüm partilerden çok daha fazla potansiyel barındırıyor. Hükümetin şu ana kadarki performansının bu potansiyele işaret ettiği açıktr. AKP'nin bu tür bir 'potansiyel' olarak 90'ların siyasetinin içinden nasıl 'evrildiği' ve seçim başarısınun nedenleri sorusu ayrıntılı siyasi -toplumsal-kültürel analizlerin yapılmasını gerektiren önemli bir siyaset bilimi sorusu olarak beliriyor. Bense burada bu zor soruyu yanitlamaya kalkışmaktansa, bu tür bir soruyu bile, AKP'yi 'gizli gündemlerini uygulamak için fırsat kollayan o eski bildik islamcı güç' olarak görmeye devam ettikleri için anlamsız bulanlara karşı, AKP'nin neden farklı bir güç, ve dahası gerçek bir 'güç' olduğuna dair birkaç temel noktaya işaret etmekle yetineceğim.

$O$ halde, AKP'nin diğer partilerle karşılaştırmalı olarak taşıdığı kapasite /potansiyel nereden kaynaklanyor? AKP'nin burjuva hegemonyasinin tesisi için taşıdığı kapasite, böylesi bir hegemonyanın kurulmasını zorlaştıran 90'ların devlet-toplum ilişkilerini kısmen de olsa yeniden düzenleme eğilimi göstermesinden kaynaklaniyor. AKP de asıl olarak, bu yeniden yapılandırma için kendinden çok, 'dışsallaştırımış' bir güce yani AB projesine yaslanmak zorunda kalsa da, yine de bu projeyi diğer partilerden daha fazla 'içselleştirme' eğilimi taşıyor. AKP'nin buradaki konumu çok karmaşık ve analiz etmesi zor bir 'oluşum'a işaret ediyor. Çünkü 90'larda islam üzerinden devlet ile ciddi gerilim 
yaşamış bir gelenek içinden evrilen AKP, geldiği noktada (ya da gelmek istediği nokta desek daha doğru olur) bu sorunu 'aşma', yani kendi hissettiği mağduriyeti daha genel bir liberal-demokrasi projesi (AB siyasi kriterleri) içinde eritme ve dolayısıyla potansiyel olarak başka benzer 'mağduriyetlere de' seslenme arzusunu dişavuruyor. Burada AKP 'oluşumunun' 28 Şubat ile bağlantısını anlamak ve ' 3 Kasım 28 Şubat'ın bir rövanşı mı yoksa devamı olarak mı görülmelidir' sorusunu yantlamak önem kazanuyor. AKP açkça bir 28 Şubat ürünü/28 Şubat dersini almış bir oluşum olarak görülmelidir. Ancak bu 'ürün' şimdi kendini, elindeki tek kozu, yani kendi toplumsal gücünü, kendinde gerçekleştirdiği dönüşümün karşllı̆̆ olarak, devlete yönelik bir pazarlık unsuru olarak öne sürmektedir. Bu pazarlık şudur: siyasal islam rotasından çkmanın karşlığı olarak, devletin/düzenin AKP'nin kendi imgesine uygun bir 'muhafazakar-demokrat' parti olmasina, merkez sağda büyük bir güç olarak yerini sağlamlaştırmasına 'izin vermesi'. Birazdan değineceğim gibi, AKP'nin ne olduğu ya da ne olacağı önemli ölçüde bu 'izine' bağlı görünüyor.

Daha genel olarak AKP'nin potansiyeli, burjuvazinin uzun dönemli hegemonik çıkarları ile halkın kısa dönemli taleplerini birbirine eklemleme potansiyeli taşıyan tek parti olmasindan kaynaklanuyor. İlk kez AB projesi bu kadar güçlü bir toplumsal desteğe sahip bir parti tarafından kitleselleştirilme şansını buluyor. Aynı zamanda AKP, büyük sermaye ile Anadolu sermayesi ve alt sinıflar arasındaki bağlantıyı da kurmaya yelteniyor. Burjuvazinin uzun dönemli hegemonik çkarının artık zorunlu kıldığı daha 'üretken' ve 'demokratik' bir düzen vaadi diğer bağımlı kesimleri bu projeye eklemlemek için bir olanak yaratıyor. Bu açıdan AKP'yi diğer partilerle olan karşıtlığına işaret etmek amaciyla, 1950'lerin Demokrat Partisi ve 80'lerin ANAP'ına benzeten yorumlara değinmekte fayda var. AKP ile CHP'yi karşıkarşıya getiren seçim sonuçları, seçmen davranışları açısından düşünüldüğünde Türkiye'de sağ ile sol kavramsallaştırmasına yönelik Küçükömer tarzı bir analizi yeniden gündeme getiriyor. AKP'nin geniş bir alt-orta ve alt sınuf kesimlerine seslenmeyi başardığı, CHP'nin ise büyük sermayenin desteğiyle birlikte kentli profesyonel orta sinuflarla sinurlandığ 1 ortada. Türkiye tarihinde bir kez daha otoriter ve sömürücü bir düzenin mağdurlarının büyük bir kısmı, mağduriyetlerini kültürel olarak kendilerine daha 'yakın' duran liberal-muhafazakar çerçevede ifade etmeyi ve böylece merkeze 'yaklaşmayı' deniyorlar.

Ancak AKP'nin arzettiği bu potansiyel ayn zamanda ve tam olarak ayn nedenlerle AKP'nin önünde önemli riskler ve engeller de doğuruyor. Risklerin tümü AKP'nin henüz bir parti (bir davanun tarafı olan, kararlı bir toplumsal güç anlamında) değil, dilek/arzu aşamasında olan bir 'oluşum' vasfını taşımasından ve üstelik düğüm haline gelmiş bir sorunlar yumağını çözmek gibi büyük bir iddianın peşine düşmesinden kaynaklanıyor. Böyle bir 'oluşumun' karşısındaki önemli engellerden birisi mevcut siyasi yapıdaki 'derin' güçlerin sergileyecekleri 
direnişle ilgili. Seçimin hemen ardından medyanın ve büyük sermayenin hükümete verdiği büyük destek, bu çevrelerin AKP'nin pazarlık önerisini kabul etmeye hazır olduklarını gösteriyor. Nitekim bu çevreler daha ilk günden AKP'nin kendi kurmaya çalıştığı merkez sağ, ANAP benzeri 'muhafakazar -demokrat', hatta 'liberal-demokrat parti' imgesini desteklemeye başladılar. Ancak bunun karşısında bu imgeyi parçalamaya gayret edecek olanlar da var. Bu çevrelerin AKP'ye yönelik öne çıkardıkları 'islamcı-şeriatç' imgesi, basit bir yanlış anlamayı/analizi temsil etmekten çok, bazı çevrelerin mücadele hattını bunun üzerinden kurmaya yönelik siyasi niyetine işaret ediyor. Bu çevrelerin beklentisi yeni bir 28 Şubat yaratılarak AKP'yi 'gerçek yüzünü' göstermeye, 'gizli gündemini' açı̆a çıarmaya zorlamak olabilir. Ancak ilk günlerdeki bu beklenti şimdilerde daha da zayıflamıs görünüyor çünkü bu çevrelerin elinde artık 28 Şubattaki kadar güçlü kozlar yok. Bunun nedeni hem CHP'nin 'pozitif' tutumunun yanısira iki partili bir meclis yapısının entrika siyasetine pek fazla alan tanımaması, hem de AKP hükümetine karşı 28 Şubat sürecindeki kadar güçlü bir 'sivil toplum' tepkisini harekete geçirmenin mümkün görünmemesi. Bu pek olası görünmüyor çünkü $A K P, A B$ konusundaki Kopenhag öncesi ve sonrasındaki açıkça başanlı performansı sayesinde 'sivil toplumun' önemli bir bölümünü arkasına almış bulunuyor. Dolayısıyla, yeni hükümetin islamcilık üzerinden sıkıştırılması stratejisinin sınırları artık daha da daralmış saylabilir. Ancak bu kez daha büyük bir risk sözkonusu çünkü karşı cephe de büyük oynamaya, bahsi büyütmeye çalışabilir. AKP'nin islamalık üzerinden değil, bu kez Kıbris, $A B$ ve Kürt Sorunu gibi hassas 'milli meseleler' üzerinden hedef tahtasına konulması olasılığı her zaman var. Bu çevreler özellikle Ağar'in DYP'nin başına geçmesiyle meclis içi bir entrika stratejisiyle daha 'milli ve laik' güçlerin parlatılması için daha uygun bir zemin sağlandığın düşünüyor olabilirler.

Yine de AKP'yi bekleyen asıl tehlike, derin devlet güçleri tarafından islamcilık üzerinden 'ötelenmesi-dışlanması' değil, tam tersine kendi kendine yüklediği 'merkez parti' baskısının artrilarak bildik anlamda 'merkeze' çekilmeye çalışılması yani 'Kıbrıs, demokratikleşme, Kürt sorunu ve laiklik gibi konulardaki 'hassas' devlet politikalarının' içine hapsedilmesi yoluyla kendi tabanı ile ilişkilerinin gerilmesine ve/veya yeni davanun gereklerini yerine getirmesine engel olunması olasılığı. AKP'nin son derece çeşitlilik arzeden ve henüz 'oturmuş' bir eklemlenme içinde olmadığı anlaşlan hassas ve oynak bir tabana dayandığı ortada. Bu hassas dengenin merkezdeki bazı entrikalar yoluyla olabileceği gibi AKP'nin fazlaca 'merkeze' kayması yoluyla da sarsılabileceği tahmin edilebilir. AKP'nin türban konusunda sıkıştırılması bunu gösteriyor. AKP açıkca türban konusunda kendi kitlesine itidal ve sabır telkin etmiş ve ikna etmiş görünüyor ancak bu iknanun, sorunun çözümünün ilelebet ertelenmesi değil, $A B$ çerçevesinde kişisel hak ve özgürlükler paketi bağlamında 
çözümlenmesi doğrultusunda olduğu da açık. Dolayısıyla sorunun bu liberal-demokratik çerçevede dahi çözümlenmesine izin verilmediği ve AKP'nin sürekli geri adım atmaya zorlandığı bir durumda bu kesimlerin hükümete tanıdıkları vadenin hızla dolacağı tahmin edilebilir.

AKP'nin üzerine oturduğu hassas dengenin, Kürt sorunu ve Kıbrıs gibi klasik otoriter-içe kapanmacı reflekslerin yoğunlaştığı konular üzerinden de bozulabileceği çok açı. 20 yıl boyunca bu tür reflekslerle şekillenmiş seçmenin AKP'nin gösterdiği/gösterebileceği demokratik açlımlar karşısında ne düzeyde ve nereye kadar olumlu tepki vereceği ve muhtemel bir 'milli' entrikanın çekim alanundan ne kadar korunabileceği de belirsiz. Yine de AKP'nin bu gibi konularda bile diğer partilere kıyasla kendi seçmeninin en azından belirli kısımların 'eğitme' kapasitesinin daha fazla olduğu da söylenebilir.

Son olarak AKP'nin tüm bu sözkonusu riskler ve muhtemel engeller karşısında direnme ve kendi oluşumunu istediği tarzda şekillendirme kapasitesini belirleyecek olan hususa, yani AKP'nin asıl yumuşak karnın oluşturan noktaya işaret etmek gerekir. Bu da hiç kuşkusuz alt sınıflar, küçük ve orta ölçekli sermaye ve büyük burjuvazinin çkarları arasındaki denklemin nasıl kurulacağı sorusuyla ilişkilidir. Şubat krizinin sarsıcı biçimde devam ettiği bir dönemde gerçekleşen seçimde AKP'ye verilen seçmen desteğinin büyük kısmının sosyal sefalet konusundaki beklentilerle ilgili olduğu açiktır. AKP hükümeti halka yönelik vaadlerini, seçim öncesinde 'niyetleri' konusunda ikna etmek zorunda kaldığı IMF çevrelerinin çizdiği yapısal sınırlar içinde kalarak ve burada yakalayabileceği manevra alanında işe biraz 'sosyal boyut' ekleyerek yapmaya çalışacaktır. Bu manevra alanunun çok geniş olmadığı ve kısa dönemde sefalet koşullarında anlamlı bir iyileşme olmayacağı ileri sürülebilir. Buna rağmen yeni hükümetin bu konuda da hem konjonktürden hem de partinin yapisından kaynaklanan avantajları olduğu da doğrudur. Bu avantajlar arasında ilk olarak Şubat krizinin ardından alınan yeniden-yapılanmaya dair kararların asıl ceremesini eski hükümetin yüklenmiş olmasını saymak gerekir. Aynca bir yandan 'duble yol' gibi kamu harcamalannin istihdam yaratic etkilerinin yanisira, bir yandan da kamuda tasarruf tedbirlerine hiz vererek elde edilecek kaynaklar, (bu konuda milletvekilleri lojmanlarının satışı ile başlayıp, askeri lojmanların satı̧ıı noktasında durmak zorunda kalsa da, kamuya ait tesislerin satışı ya da kiraların artırılması örneğindeki gibi, hem yoksul halk kesimlerinin 'ayncalıklara' dönük öfkesine seslenen hem de kaynak üreten stratejilerin önemine değinelim) ile yerel yönetimler düzeyindeki popülist stratejilerin yoksul halk üzerindeki etkilerini de işaret etmek gerekir. 'Popülist' denip geçilmemesi gereken bu stratejiler, hem yaşanan yoksulluk düzeyinin gerektirdiği her tür acil desteğin taşıdığı 'meşruiyet' açısından hem de AKP'nin seçmeninin kendine tanıdığı vadeyi uzatma şansı açısından değerlendirilmelidir. AKP'nin yoksul halk kesimleriyle kurduğu bu ilişkinin genel olarak sermaye 
güçleriyle kurduğu yakın ilişkinin bağımlı bir değişkeni olduğu açı. Burada da yeni hükümetin orta ve küçük ölçekli sermaye ile büyük burjuvazinin çkarları arasında bir eklemlenmeye gitme gayreti göstermesi önem taşıyor. Büyük sermaye asıl olarak uzun dönemli hegemonik çıarların gerektirdiği yapısal dönüşümlerin sahiplenilmesi üzerinden yakalanmış bulunuyor. (tabii buna mali milat'ın ertelenmesi gibi uygulamaları da eklemek gerekir.) AKP'nin tabanının kurucu unsuru olan orta ve küçük ölçekli sermayenin ise her durumda hükümet tarafından kollanacağı (örneğin hükümetin Kamu thale Yasasına yönelik asıl eleştirisi, yasanın büyük sermayeyi kollayan tekelci hükümlerden kaynaklanuyor) da anlaşılıyor.

Sonuç olarak henüz oluşum halindeki bir güç olarak AKP'nin karmaşık ve hassas dengelerinin hem kendi içinden hem de diğer güçlerin ona yönelik benimseyecekleri stratejilerden kaynaklanan çeşitli nedenlerle bozulması çok muhtemel. Ancak AKP'nin pazarlık önerisinin reddedilmesi ve merkeze oturmasınun engellenmesi halinde bile partinin asla 28 Şubat öncesi bir islami kimliğe geri dönmeyeceği, bu eşiğin onlar tarafından atlanmıs olduğu söylenebilir. (Bu tesbit, AKP iktidannda, zaten uzun zamandur koyu muhafazakar-gerici bir yapılanmaya sahip taşrada bazı çevrelerin kendilerini daha rahat hissetmeyecekleri anlamına gelmiyor.) Dolayısıyla, bu yazıda sözünü ettiğim hegemonik projenin sahibinin AKP olmasının engellenmesi durumunda bu dava kendisini üstlenecek yeni sahipler bulma arayışına devam edecektir. Işlerin AKP lehine gelişmesinin daha büyük bir olasllık gibi görünmesinin temel nedeni, mevcut tüm diğer merkez sağ-sol partilerin, kitlesel desteği de olan bir liberal-demokratik siyasal dönüşüm projesini yürütme kapasitesini sergilemiyor olmalarıdır. Türkiye toplumunun adalet, özgürlük ve barış özlemlerini sol bir $A B$ hedefi bağlamında kitlesel olarak örgütleme becerisini gösterecek bir sol aiternatifin gelişmediği durumda - ki ne yazık ki mevcut yapılanma kısa dönemde hiç de umut vaadetmiyor- AKP hükümetinin kısa dönemdeki tek muhtemel alternatifi otoriter-devletçi bir yeni 'oluşum' olabilir. Bu tür bir yeni 'oluşum' için en muhtemel aday, hiç kuşkusuz Ağar liderliğinde artık ANAP'la değil de MHP ile birleşmesi akla yatkın olan DYP'dir. Ancak akla ilk gelen ve elde hazır bulunan bu seçenek, muhtemel/müstakbel başarısını sadece, statükonun aynen korunmasında siyasi-iktisadi fayda gören güçlerin toplumun içe-kapanmacı reflekslerini kışkırtmaya dayalı entrika siyasetindeki ustalık düzeyine borçlu olacaktır. Ancak böylesi bir 'başari' kuğunun son şarkısı olmaktan kurtulamaz, çünkü bu atılımın uzun vadedeki sonucunun liberal -demokratik kampın güçlenmesi olması çok daha muhtemeldir. Öte yandan Türkiye'nin kangrenleşmiş bunalımının sürüncemeye bırakılması, zorunlu olarak yaşanan sosyal sefaletin artmasıyla sonuçlandığında da bu kez küresel entegrasyon projesi, karşısında Genç Parti türü neo-faşizan bir güç bulacaktır. 


\section{'Burjuva hegemonyası'na dair kişisel bir not:}

Bazı okuyucular bu yazıda sunulan analizin 'burjuva hegemonyasını' etkisi altında yapıldığın düşünebilirler. 'Burjuva hegemonyasının' 'çok kötü bir şey' olduğunu düşünen bazıları ise 'burjuva hegemonyası' adı altında analiz edilen bu süreçlerle yazarın cepheden karşıt olma dışında bir ilişkisi olamayacağını varsayacaklardır. llk gruba girenlerin, yargılarında 'haklı' olmamakla birlikte daha 'dikkatli' okuyucular olduğu söylenebilir. Çünkü onların da farketmiş olduğu gibi bu yazıda Türkiye'nin son yirmi yıllık dönüşümü ve mevcut durumu ağırlıklı olarak radikal bir eşitlik ve özgürlük projesinin bakış açısından çözümlenmiş değildir. Tersine giderek daha netlik kazanan ana çatışma ekseninin liberal-demokratik kamp ile otoriter-devletçi kamp arasında kurulduğu varsayımından hareket edilmiştir. Bunun nedeninin, Türkiye'nin sorunlarının en iyi bu iki kamp arasındaki çatışma üzerinden ve 'liberal-demokrat' bir proje temelinde çözüleceğine inanmam olmadığını belirtmek isterim. Tam tersine, bu kamplaşmanın olduğu gibi Türkiye'nin tüm temel sorunlarınun da derininde, kendi adına konuşma, kendi özerk söylemiyle siyasal arenaya damgasını vurma şansını henüz bulmamış olsa da, Türkiye halkının çok derinden hissettiği eşitlik ve özgürlük sorunlarının bulunduğunu düşünüyorum. Bu sorunlar bugün ve gelecekte en gelişmiş bir liberal-demokrat 'burjuva hegemonyasının' vaadedebileceğinin çok ötesinde radikal çözümler gerektiriyor. Ancak her tür toplumsal sorun, ancak belirli bir konjonktürdeki belirli siyasal özneler tarafından belirli biçimlerde ifade edildiği şekilde ve kadar 'vardır' ve çözümü de bu somut güçler dengesinin elverdiği kadardır. Bu yazının burjuva hegemonyasına karşı radikal bir alternatif perspektifinden yazıl(a)mamış olmasının nedeni bugün ana çatışmanun böyle kurul(a)mıyor olmasindan kaynaklanyor. Ancak bunu söylemek yeterli değil. Çünkü birçokları, bu tür bir alternatif peşinde olan insanlar için mevcut kamplaşmanun bir anlamı ve değeri olmadığı ve her iki kampa da aynı mesafede olunması gerektiğini düşünüyorlar. Herhangi bir kampın hegemonyası altına girmeden kendi özerk kimliğinizi vurgulamak siyasi alanda bir güç olmanın şartıdır elbette. Ancak ben, Türkiye'de mevcut kamplaşma taraflardan 'biri' lehine çözülmediği sürece, yani liberal de olsa temel bir demokratik çerçeve yönünde adım atılmadığı, asıl olarak siyasal alan biraz olsun 'açılmadığı' sürece, herhangi 'ileri' bir alternatif için bir şans olmadığın düşünüyorum. Bu eşik atlandığı zaman, adalet ve özgürlük taleplerinin daha sahici ve doğrudan bir ifadeye kavuşup kavuşmayacağı sorusu da yine siyasal güçlerin konumlanışlarına bağlı olacaktır.

Son olarak, liberal-demokrat/otoriter-devletçi kutuplaşmasının 'demokratik' çözümünün, bu denklemin kendi terimleri içinden mümkün görünmediğini, salt bu 'eşiğin' atlanmasının bile halkın kendi eşitlik ve özgürlük taleplerini öne sürmesi şartına bağlı olduğunu söyleyerek bitirmek istiyorum. 